\title{
Assessing the Need of Adaptive Changes for Emerging NORCs in Urban India
}

\author{
SUTAPA DAS ${ }^{1}$, MOUSUMI GUPTA $^{2}$, SHIVASHISH BOSE $^{3}$ \\ ${ }^{1}$ Assistant Professor, Department of Architecture \& Regional Planning, IIT Kharagpur, \\ Kharagpur 721302, India
}

${ }^{2} \mathrm{Ph} . D$. Scholar, Department of Architecture, Jadavpur University, Kolkata 700032, India

${ }^{3}$ Professor, Department of Architecture, Jadavpur University, Kolkata 700032, India

\section{Email: sutapa.d@gmail.com}

Received: November 08,2015। Revised: December 14, 2015। Accepted: February 08, 2016

Published online: July 04, 2016

The Author(s) 2016. This article is published with open access at www.chitkara.edu.in/publications

\begin{abstract}
Due to population ageing, today's high-rise apartments in Indian cities, which are currently mainly owned by young professionals, will turn into naturally occurring retirement communities (NORCs) in near future. Though many urban housing complexes of 1970s and 1980s are already serving as NORCs, the term is comparatively new to Indian housing research. This huge existing housing stock is inadequate for special gerontological needs of the elderly, who are fragile and socially vulnerable. Informal opinion of common people revealed that holistic requirement for elderly in housing is still grossly confused with vertical transport, i.e., elevators, and little attention is paid to other architectural features. As part of an ongoing doctoral study, a detailed literature review was undertaken on the vulnerability profile of Indian urban elderly in the context of special requirements of barrier-free housing. This article aims to establish the urgent need to assess the adaptive potential of existing housing communities serving as NORCs in Indian cities, such that new housing in the future can be planned with flexible approach.
\end{abstract}

Keywords: Aging of population, Urban India, NORC, Adaptive Changes, Elderly Housing, Barrier-free.

\section{INTRODUCTION}

Globally, the escalation in elderly population with age of 60 years or above has surpassed the population growth in general by $116 \%$ annually, combined with an expected hike in median age from 28 in 2010 to 38 in 2050 [57]. Such a social transition, from high mortality-high fertility to low mortalitylow fertility, is termed as population ageing. Though the developing world

Creative Space (CS)

Vol-4, No-1

July 2016

pp. 115-132

CHIIKARA 司

(C) 2014 by Chitkara

University. All Rights

Reserved. 
Das, $\mathrm{S}$

Gupta, M

Bose, $\mathrm{S}$

needs another four decades to reach the present aged status of the developed world, the phenomenon of population ageing has become faster in the developing countries. As a result of this and also due to the paucity of other resources, these nations too will face more hardships in adjusting to the consequences.

India, in its Census of 2011 [29], for the first time since its independence in 1947 , has recorded sharpest decline of $3.7 \%$ in population growth rate between 2001 and 2011. During this time-span, it has also noted increase in (a) life expectancy from 65 years to 66.8 years and, (b) rise in the number of senior citizens from $7.5 \%$ to $8.0 \%$. The latter is expected to be $12.5 \%$ by 2025 [40]. The old-age dependency ratio (i.e., number of persons aged above 60 years per 100 persons in the age-group of $15-59$ years) in India so far is 10.46, which reflects higher social dividend compared to developed countries. The traditional structure of Indian joint families where elderly people were respectfully looked after by children or grand children [38] is changing, primarily with the youth settling away from their hometowns due to social or professional reasons. NSSO reported in 2006 that $10.4 \%$ seniors lived with spouses and $4.3 \%$ lived alone where single ladies had a higher share [35].

The unprecedented, pervasive reality of ageing [57] has a challenging effect on socio-economic structure with huge financial burden on the government [2]. UN International Plan of Action on ageing [56] suggests a three-pronged strategy: (1) inclusion of the elderly in development process (2) provision for geriatric health and well-being and, (3) creating positive strategies that can enable supportive environments for elderly. The last one further suggests:

- 'Ageing in place' within the community as per individual preferences and affordability.

- Specially designed housing to facilitate independent living even for elderly with disabilities.

India has adopted these strategies very recently [50]. But the existing housing stock with no such purpose is a huge resource that claims attention for an agefriendly adaptive reuse. As an initial outcome of an ongoing Ph.D. research, this article aims to explore this issue with a focus on multi-storey apartment complexes of Indian megacities.

\section{VULNERABILITY OF INDIAN ELDERLY}

Before we embark on analysing the suitability of housing for the current elderly population of India, it is essential to understand their specific needs in terms of vulnerability. A higher life expectancy as marked by population 
ageing doesn't necessarily mean a better quality of life. At old age, even a well-bodied and healthy person experiences some form of diminished ability commonly referred as disability [53]. Among Indian elderly, these are mainly: loco-motor $(28.9 \%)$, hearing loss $(13.9 \%)$, blindness (10.9\%), low vision (4.6\%), speech (2.2\%), both hearing and speech (1.4\%) [32]. Mental illness and mental retardation are found among $1.7 \%$ and $0.7 \%$ of the senior Indian population respectively, while in terms of mobility, $1.7 \%$ males are confined to bed and $5.1 \%$ are confined to home. For female senior citizens, these values are $1.7 \%$ and $8.3 \%$ respectively as per National Sample Survey, 60th Round, [34]. Only one third of the sufferers have such disability since birth and rest have acquired it with age [33].

Such gerontological issues were present in olden days as well, but had a different perspective. Traditionally, Indian elderly had a respectful and prominent place -- within the family and in society -- as archives of wisdom, experience, culture and religious legacy [40]. Supervising the upbringing of children, maintaining societal responsibilities, soliciting expert judgement in conflict resolution or nuptial match making, etc., were common duties of the seniors [55]. At mature age, men and women used to retire from jobs of breadearning and daily household chores respectively and, were more active in social or religious life in community gatherings. Accordingly, every community or neighbourhood used to have some dedicated public spaces for their use.

In modern urban India, such joint families or the traditional close-knit community structure is vanishing fast. Its effect can be manifold and the future of Indian elderly can be predicted from the scenario of developed nations. Mellor et al. (2008) describes social isolation, migrant status and inability to communicate as severe stressors that are responsible for specific psychiatric illnesses and senile dementia of Alzheimer's type (SDAT), depression, paranoia or suicidal tendency, etc. [45]. It was observed that reduced interaction with the outside world gradually sucks out confidence in going out alone despite a moderately good health and alert mind. In such cases, social interaction with like-minded people either physically or electronically may help [4].

Apart from psychological barriers, frequent physical ailments such as diminished sense of balance, hearing or eyesight, cardiovascular disease, hypertension, stroke, lower level of immunity and cancer also occur. Problem in joints makes daily chores difficult as reported by $35 \%$ of the urban elderly [34]. Studies from the West show basic household jobs such as cleaning, washing, replacing fused bulbs, pest control, etc. can be arduous [42] and unforeseen maintenance-repair works can pose immense hassle. It is no wonder that dead batteries of smoke alarm are not replaced in many elderly households [20]. They are, thus, especially vulnerable to fire hazards due to
Assessing the Need of Adaptive Changes for Emerging NORCs in Urban India

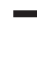


Das, $\mathrm{S}$

Gupta, M

Bose, $\mathrm{S}$

slower detection, risk response and evacuation $[8,61]$. During the last decade, cognizable crime against senior citizens has increased from $19.6 \%$ to $24.6 \%$ and, in several cases, the abuse and homicide is committed by the helping hands or some known accomplice [22].

Chaudhuri and Das (2014) reported that, in India, there is no single point of contact for an emergency and, different authorities need to be contacted different types of crisis [11]. Such contact details are confusing as such organisations have websites for internal operations rather than for public service and, sometimes they even have multiple websites. Often, the responsibility for taking take any action is delayed due to arguments over jurisdiction between two police stations or between multiple departments, such as police, fire brigade and municipal corporation. Even for booking a cab, taxi operators such as OLA or Uber require people to use Mobile Apps that work with internet-enabled smart phones. On the other hand, getting a flag-down traditional taxi is equally tough due to frequent passenger refusal. This situation is mind-boggling even for a young person, leave aside an elderly with impaired faculties.

Urban India is undergoing a transitional phase where a few traits of developed world, such as nuclear household or longer life expectancy, have arrived but the public infrastructure to cater to the growing numbers of senior citizens is yet to be seen. Hence, at the micro level, i.e., at the house or community level, some adaptive changes are essential.

\section{INDIAN HOUSING SCENARIO AND THE ELDERLY}

Urban population in India has swelled up by $250 \%$ in last four decades [29]. By $2020,40 \%$ of Indians will live in cities [44]. The country's construction industry, with its fast annual growth rate of $9.2 \%$ vs. $5.5 \%$ of global average [25], is primarily dominated by the residential sector [6]. The concept of low rise-low density cities is swept away by high rise-high density 'compact cities' of vertical growth $[24,37]$. Presently, $75 \%$ of new high-rise developments are residential properties $[17,19]$ catering to various strata of the society [37].

However, in this boom of the housing market, the senior group exists in prominent obscurity. Till date, housing for the elderly has received very less specific attention in policy making in terms of social, economical, healthcare or physical planning aspects [40]. Some exceptions are listed as under [31]:

- Integrated Programme for Older Persons, 1992, 2008, 2015: It promotes capacity building of non-govt organisation to provide shelter, food and healthcare to the elderly. It mainly covers maintenance of old-age homes and care-homes. 
- National Policy on Older Persons, 1997, 2011: It proposes (i) reservation of $10 \%$ units and ground floor units in affordable housing schemes; (ii) age-friendly, barrier-free public spaces for more social interaction and its implementation through standards and codes; (iii) special group housing with common services and, (iv) soft loans to elderly for purchase and major repair of house.

- Maintenance and Welfare of Parents and Senior Citizens Act, 2007: This act makes it mandatory to have at least one old age home for indigent senior citizens (with a capacity of 150) in every district of the country. But its previous scheme named 'Assistance for Construction of Old Age Homes' of 1996 for 50\% cash subsidy of construction cost was abandoned in 2006-07 because of poor response from the implementing agencies.

However, the success of these schemes is questionable. While the country has around 24.7 million housing shortage on an average [30], it is odd to venture in exclusive elderly housing. Also, in the Indian context, people seldom prefer to leave their home and familiar neighbourhood at old age. Moreover, researches show that compared to relatively expensive nursing homes or retirement homes, home stay leads to better performance in basic activities, cognitive functions, depression, incontinence and other common ailments [43]. People feel more safe, secure and independent in the familiar environment of home [21]. From these facts, it can be inferred that for ageing-in-place or growing old in own homes is an essential concern for urban India but has not received much attention so far.

\subsection{Emergence of NORCs}

The residential properties that have emerged in Indian cities in recent decades are mostly multi-storey apartments, which are predominantly owned by young, first time home buyers such as single professionals or newly married couples. However, in the near future, these young owners will become senior citizens and will be staying in 'naturally occurring retirement communities' (NORC). The NORC is defined as "housing developments that are not planned or designed for older people, but which over time come to house largely older people" [27]. This Western concept has now gradually spread to Australia and few countries in South-east Asia [5]. In India too, NORC will be a buzzword very soon due to rapid population ageing and breaking up of joint families into several nuclear households. In fact, authors have observed that many of the government-sponsored housing developments of 1970 onwards are already serving as NORCs, even though this topic is in a nascent stage of research.
Assessing the Need of Adaptive Changes for Emerging NORCs in Urban India

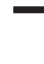


Das, $\mathrm{S}$

Gupta, M

Bose, $\mathrm{S}$

\subsection{Perception of High-Rise Living}

High-rises or tall buildings can be defined in various ways in terms of structural stability, ease of evacuation, maintainability, etc. [15]. In India, a 15 meter high building which is not walk-able and needs an elevator is considered as tall [7]. In that sense, most of the urban housing societies in India are of the high-rise category. In practise, people's prior living experience determines the perception of tallness and links it to the pros and cons of living in them. In his famous theory of 'Defensible Space', Oscar Newman (1972) associates building height with higher crime rate owing to lack of personal control or responsibility for vast public spaces[47]. Several later studies question this thought. For example, Normoyle and Foley (1988) prioritized law and order in the neighbourhood over the building height[49].

In a detailed study on psychological, behavioural and interpersonal influences of high-rise living, Gifford (2007) observed coexistence of both positive and negative attitudes. Phenomena such as dissatisfaction, stress, behaviour problems, suicide, poor social relations, reduced helpfulness and, hindered child development, etc. are attached to high-rises as 'disgrace'. Fear of crime, being trapped during fire, collapse of the structure by earthquake or terrorist attack, higher chance of communicable diseases were also reported, which though are prevailing myths rather than scientific facts. On the contrary, the positive feelings expressed by residents include factors such as more open space, less noise and pollution, better view, more privacy, proximity to downtown, less maintenance for outdoors, professional surveillance, etc. [23].

In a recent American Housing Survey [9], very seniors (of over 85 years) preferred to stay in a large building (more than 21 units) for enhanced scope of social interaction, systematic healthcare and building services, especially the elevators. Vertical NORCs of big cities outscored horizontal NORCs of suburbs due to distinguished group identity, accessibility to services, economic operation and maintenance of the home. Most surprisingly, vertical NORCs showed better social connectivity compared to scattered neighbourhood [5]. As over time, the willingness to live higher progresses with the growing familiarity [62] that high-rise living experience can be made more welcoming with physical planning and technological enhancements. This idea is also supported by Cho and Lee (2011) who noticed that residents of Korean highrises are more satisfied when provided with community spaces for social program and interaction [13].

In India, such in-depth studies are yet to emerge. Chatterjee (2009) compared housing environment perception (HEP) of high-rises (above 5-storied) against low-rises using twenty-five parameters. Irrespective of respondents' age, high-rises scored low in general and the specifics of hygiene, thermal comfort, 
inconvenience, security, floor area and cleanliness of the locality. At the same time low-rises were marked as noisy, poorly lit and indisciplined [10]. In general, growth of dissatisfaction with people's age may be due to diminished ability to adapt to the environment. Based on preliminary studies, Muhuri and Basu (2014) mentioned that social interaction spaces are very important, but may need variation depending on user types and building typology [46].

\section{ADAPTIVE LIVING FOR AGEING IN PLACE}

Usually with age, people's adaptive ability decreases and, hence, providing for 'ageing in space' through adaptive changes becomes a challenge for the architects, planners or sociologists. Argoud (2011) comments that the "quality, suitability and adaptability" of the dwelling unit is a fundamental requirement for enabling healthy ageing in place [1]. Elderly housing, in most of the countries, can be primarily categorized into (1) institutional care for illness and incapacity [52] and, (2) ageing in place or growing old at home [59]. Though the latter is more preferred due to economy, familiarity, sentimental connection with the home and neighbourhood, it needs to overcome a few drawbacks, such as arranging reliable caregiver or health services, spiralling cost of maintenance and, expensive adaptation or alteration to fight functional obsolescence. The aged may find the normal spaces such as bath, entry steps or storage racks beyond a certain height range difficult to use. To solve this problem the house and its essential services need to be enhanced by smart technologies and/or undergo physical remodelling. But in both cases, such alterations are cumbersome, especially if the original house lacks such flexibility. As a result the seniors adapt to the existing situation [52].

\subsection{Smart Home Technologies for the Elderly}

Recently, smart technologies have penetrated into the realm of elderly homes in most of the developed countries. Its gained benefit of safety-security, followed by the indoor environment control and health-related system, is favoured in Korea [39]. In Norway, three separate surveys conducted by Toril Laberg and her team [41] revealed the following advantages of smart home technologies:

- A more convenient life and reduced feeling of disability.

- Sound sleep as curtains and windows are automatically closed or opened.

- Less pain in limbs as many daily chores (door opening, switching on light) are automated.

- Cost of living in a smart home is half the cost of staying in nursing home. 
Das, $\mathrm{S}$

Gupta, M

Bose, $\mathrm{S}$

- Disturbance produced by calling bells, mid-night checking, etc. of caregivers are greatly reduced.

- Caregivers feel more relaxed as any emergency is conveyed instantly through SMS or alarm.

Similar preferences for technology-enabled independent living have been reported from other parts of the world $[4,12,16]$. Several academic and commercial projects/systems have been covered in these, for example, WellAWARE, AlarmNET, GatorTech Smart House, Aware Home by Georgia Tech, Assisted Living Project, Assisted Cognition Environment, CodeBlue, ORCATECH, MavHome, etc.

Most of these systems -- known as ubiquitous system -- use the principle of sensors or detectors spread all over the house [51] or, are worn by the elderly residents. The sensors track the movement, other activities or health related data. This information is sent wirelessly to a central unit or a website and compared with the baseline of normality. Any abrupt deviation sends alert to the caregiver or doctor [26], while the basic, regular instructions are communicated to the elderly directly using auditory and visual prompts. An alarm is also raised against risky situation such as a fall or a fire. Additionally, smart technologies link the homebound seniors to outside world electronically [3]. These systems or technologies can be broadly classified into three groups with some overlapping functions namely:

- Supportive: Dementia reminders, stair-lift, video doorbell, drug dispenser unit, personal heating system, therapy units (e.g., pacemaker, dialysis machines), etc.

- Responsive: Panic pendant, fall detector, incontinence monitor, cardiotachometer, gas or smoke detector, chair/bed occupancy monitor, etc.

- Preventive: Fall prediction, transfer and event monitoring, general gradual decline, activities of daily living (ADL) monitoring, etc.

Such technologies are yet to come to India. The reasons are manifold. Firstly, lower old age dependency value of 10.46 makes professional help or younger family members still available as caregivers. Manual labour is cheaper than gadgets for many household jobs. Secondly, out of $76 \%$ of male and $42 \%$ of female urban elderly (NSSO, 2008) who received formal education, many are not sufficiently tech-savvy to use a computer, possess an email account or are comfortable with texting or ATM [11]. Even in developed countries such as Australia or USA, most of the elderly are afraid to use computers, internet or IT enabled smart devices $[14,45,48]$. As a third reason it can be noted that the cost for smart technologies are high, many residences need installation of 
the same from scratch and, after-sales service may be poor as laws to protect consumers are used less frequently and the legal procedure is slow. Lastly, it can be assumed that reliability, inter-operability, confidentiality and userfriendliness of public services such as the fire brigade, police or emergency services that are to be linked to these smart devices is also questionable [11].

\subsection{Strategies for Physical Planning}

In this current Indian context, choosing an option of 'physical planning of the home environment' may be more appropriate than that of 'smart technologies'. But the designs should have some embedded preventive or in-built strategies for adaptive physical planning and future plugging in the smart devices. This concept of modified settings for the elderly germinated with the idea of physical planning for barrier-free environment. Its initial focus on disabled persons now also includes the elderly as well as the sick. The most common features used for barrier-free environments are [58, 54, 60]:

- Access Related: Ramps, wide passages, wide doors for wheelchair movement; tactile or coloured warning indicators at change in level or direction, handrails/grab bars, levelled skid-resistant flooring, etc.

- Services Related: Lift control buttons with Braille and tactile markings at lower level, platform or wheelchair stair-lift, adequate number of toilets, sufficiently bright lights but without glare, noise control measures, power backup, etc.

- Space Related: Frequent resting or sitting place, large bold signage, less cluttered areas, contrast in colour to identify level/direction change, spaces for socialization or interaction, etc.

Apart from these features, it is very important to have spaces for social interaction along with a provision for physical fitness, which can be incorporated even for high-rises. For example, common areas can be planned not only at the ground floor but also at intermediate floors or at terrace level. A fire refuge floor lying vacant during usual days can serve the purpose. A small piece of area in front of every apartment that opens on to such porch-like interaction zones can be left for gardening or similar activities by the residents. Sitting arrangements, acupressure pebble pathways, a corner for watching TV or indoor games, or tea session gatherings, etc. can be arranged in the common areas to promote and accommodate social interaction and physical activities. Even the traditional congregation place for religious activities can be brought back to a modern scale. Access related issues can also be solved to a great extent by adding elevators to an existing building.
Assessing the Need of Adaptive Changes for Emerging NORCs in Urban India

$\overline{2}$


Das, $\mathrm{S}$

Gupta, M

Bose, $\mathrm{S}$

\section{CHALLENGES IN INTRODUCING ADAPTIVE CHANGES}

Studies from the developed world have shown that small adaptive changes in the living environment can boost self-esteem, confidence and feeling of security of the elderly $[21,28]$. However, the existing housing stock already serving as NORC can pose a hurdle for adaptive reuse because when these were designed, no one might have envisioned its functional obsolescence as NORC. As discovered by the authors, apart from technical barriers, human barriers are also palpable.

As mentioned in earlier sections, the term NORC is still not harshly felt en-mass due to India's relatively high social dividend and, as a result, finegrained research on age-friendly adaptive housing for the Indian context is yet to emerge. This fact became obvious when this topic was discussed with seven experts from the practitioner-academician community with more than 15 years of experience. In another discussion session, opinion was sought from 18 elderly users staying in Golf Green Housing Estate located in southern part of Kolkata. This is one of the large housing complexes developed by West Bengal Housing Board in five phases between 1978 and 1983. Senior, retired owners now predominantly occupy it. In those days (1070s and 1980s), apartment buildings were mostly government funded or were 'company housing'. The second category, by its definition, cannot act as NORCs. Both respondent groups' main concern was focussed on vertical accessibility. The designer community showed additional concern for the constraints of installing an elevator in a stand-alone apartment on a tight site or for affordable houses where installation and running cost of an elevator is not feasible.

For the existing housing stock, the redesign challenge comes in various forms. For example, let us consider the accessibility issue of the housing complex for which the residents were informally interviewed. Though the complex was developed in phases, unfortunately there was no special consideration for agefriendly environment over the years. In Fig. 1, the entry point of flats of Phase I is submerged in a thin layer of water. The situation is the same throughout the year because there is a no dedicated walkway connecting the entry point with internal roads. The approach roads have been elevated over the years due to topping by new layers of macadam (in the name of repairs), leaving the green space and entry point of the building at a lower level.

Fig. 2 highlights the undesirable effect of extension in the Phase II flats. The existing balconies are now being converted into rooms. It increases the floor area, but reduces entry of natural light and ventilation to some existing rooms. These two elements are essential for the wellbeing of seniors, especially for people suffering from Alzheimer's disease and breathing problems 


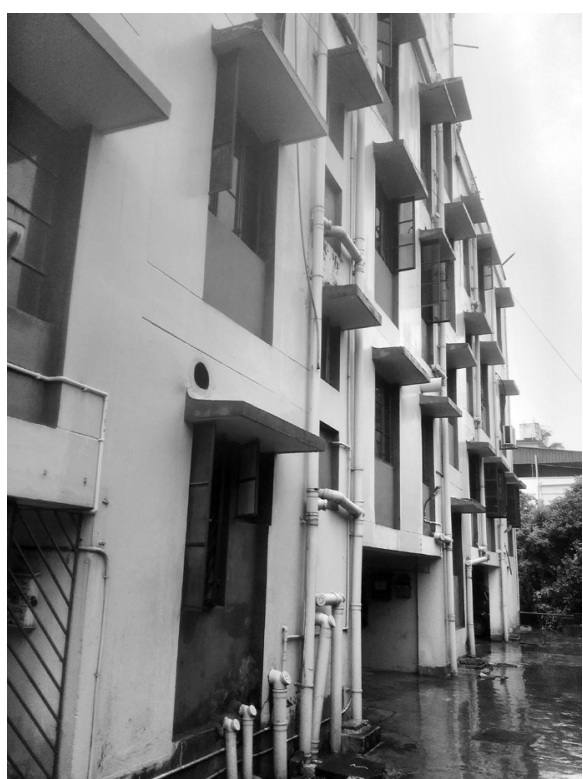

Figure 1: Entry to Phase I flats remains submerged in water all year round, making access to flats difficult and hazardous.

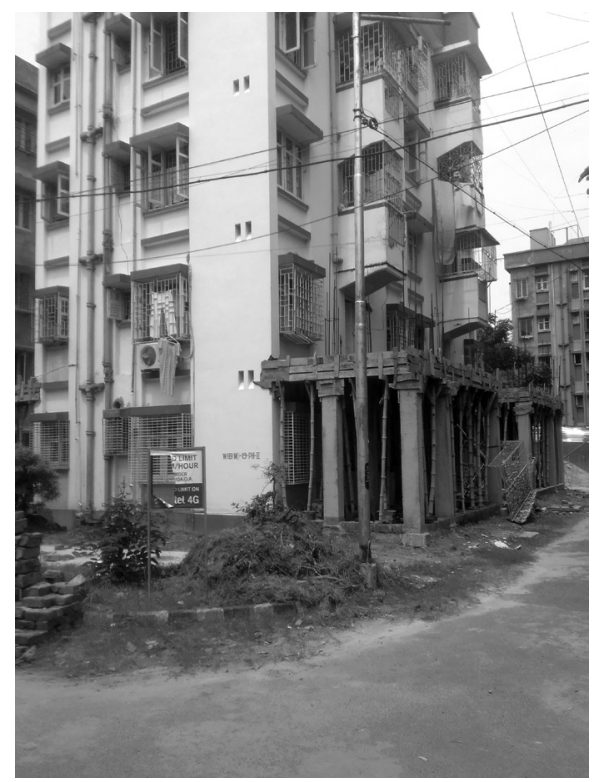

Figure 2: Extension work and covering of balconies in Phase II flats makes rooms dark and stuffy, and unsuitable for healthy living.

respectively. As the balcony gets converted to a room, the social interaction and visual access enjoyed by homebound elderly are greatly diminished. The green spaces adjacent to the buildings have disappeared and the buildings abut directly on the internal roads. As there is no dedicated walkway, people need to share the roads with moving vehicles. It is dangerous for the frail elderly who moves slowly with unbalanced gait and cannot respond fast to an incident.

Fig 3 shows a roadside parking in buildings of the Phase III. Since vehicles are parked on a two-lane internal road, no walkways for pedestrians are available. Also, no shade or outdoor resting areas have been provided along the internal roads. In the next figure (Fig. 4), the entry point and external wall of the staircase of the same building can be seen. The skin is made of concrete jail, which reduces daylight but allows lashing rain. Airflow through these jails is negligible as there is no opening on the opposite side of the staircase. As a result, the narrow stairway (with a nominal clear width $850 \mathrm{~mm}$, due to use of a brick balustrade) remains dark and slippery. Its inadequate width does not allow fitting of grab-rails on the walls. When these points were discussed with the residents and the professionals, they agreed that these too are highly 


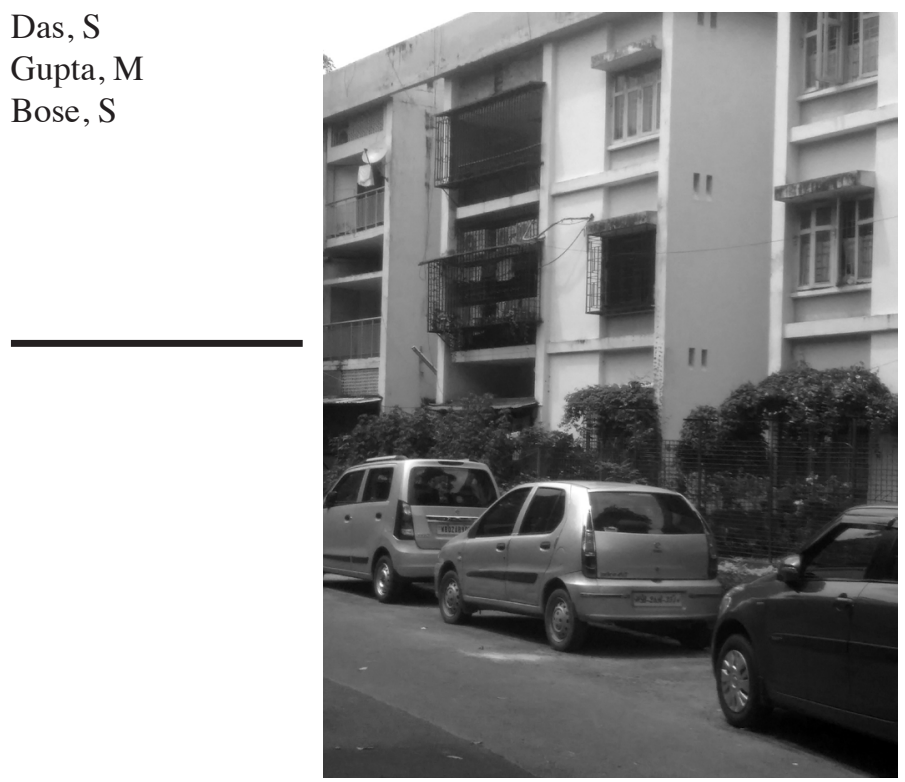

Figure 3: Parked vehicles on the road in Phase III has reduced walkable zones for pedestrians and created hazards for elderly.

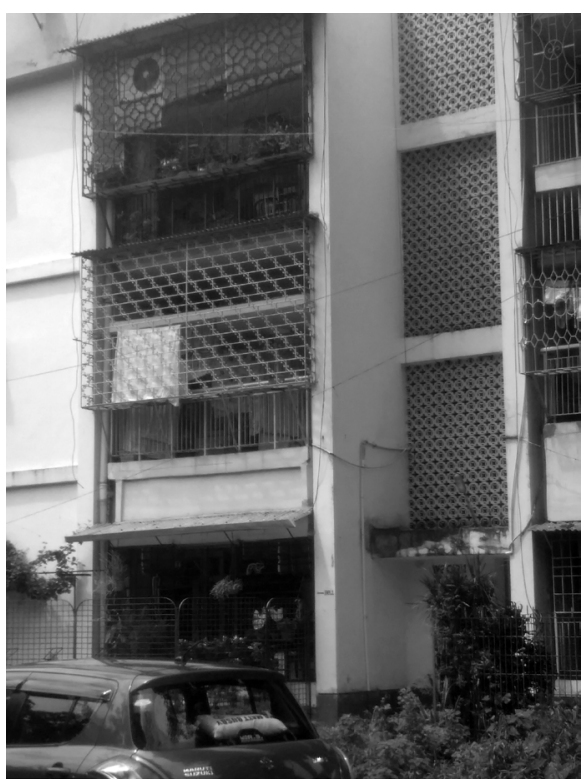

Figure 4: Use of concrete jali in staircases does not prevent access of lashing rain but reduces light and ventilation in stair halls.

bothersome, in addition to the single issue of vertical access highlighted by them.

Hence, the authors inferred that neither the designers nor the end users are well-versed with the holistic aspects of age-friendly houses or, the concepts of adaptive reuse of a normal home. Though people subconsciously agreed to other features, but were unable to precisely define the requirements. When the options of special type barrier-free elevators (e.g., pneumatic, chair, platform, straight and curved run porch lift, etc.) were discussed, it was unanimously agreed that technical solutions are available even for stand-alone, detached houses, but vertical access is just a part of age-friendly environment. Why else would the elderly in high-rise NORCs with good vertical access face hardships about other factors of living arrangements? Also it can be argued that adaptive reuse cannot cater to aging at home for severely disabled person needing intensive hospice care. Hence, it is of higher priority to develop a decision support system for (a) selecting the options for a flexible housing which is to be designed from scratch and, (b) adaptive strategy of an existing one. 


\section{CONCLUSION}

This article elicits the findings of a preliminary stage of doctoral research on Indian NORCs. It discussed the ageing profile of urban Indian society, its vulnerability and special needs. From the detailed discussion, the urgent need to assess the adaptive potential of existing residential multi-storied towers serving as NORC in Indian cities was established. Along with this, it also inferred that it is essential to promote housings that must have special policies, flexible designs or planning methodology for age-friendly adaptive reuse. Both cases will receive a boost from the fact that a close network of services and support systems in a high-rise is easier and cheaper to achieve rather than in a scattered neighbourhood. Hence, physical planning through interactive common areas connecting the elderly residents should be emphasized.

However, the current scenario of a fast depleting social support and manpower now requires that the smart technologies become affordable and available inexpensive devices such as CCTV network, intercom, burglar alarm, etc., which are in profound use in offices, can be used successfully in the residential units. Once prices for other smart technologies begin to fall, these can be slowly introduced in phases as per the residents' preference. As culture plays a big role in defining occupants' satisfaction in a built environment, a generic design may not be recommended. Here, study of the social context of occupants, which varies for users from different backgrounds, is also important because machines cannot understand this vital factor.

\section{REFERENCES}

[1] ARGOUD, D. (2011) Accommodation habitat: an ambiguous evolution. Gerontology \& Society, 136, pp. 13-27.

[2] AUSTRALIA. s:

[3] BAL, M., SHEN, W., HAO1, Q. and XUE, H. (2011) Collaborative smart home technologies for senior independent living: A review. In: Proceedings of the 15th International Conference on Computer Supported Cooperative Work in Design (CSCWD), Laussane, 08-10 June 2011. New York:IEEE, pp. 481-488

[4] BRADLEY,N., and POPPEN, W. (2003) Assistive technology, computers and Internet may decrease sense of isolation for homebound elderly and disabled persons. Technology and Disability, 15 (1), pp. 19-25.

[4] BRADLEY, N., and POPPEN, W. (2003) Assistive technology, computers and Internet may decrease sense of isolation for homebound elderly and disabled persons. Technology and Disability, 15 (1), pp. 19-25.
Assessing the

Need of Adaptive

Changes for

Emerging NORCs

in Urban India 
Das, $\mathrm{S}$

Gupta, M

Bose, $\mathrm{S}$

[5] BRONSTEIN, L. and KENALEY, B. (2010) Learning from vertical NORCs: Challenges and recommendations for horizontal NORCs. Journal of Housing for the Elderly, 24 (3-4), pp. 237-248.

[6] BUREAU OF ENERGY EFFICIENCY (2009) Energy Conservation Building Code (ECBC) - User Guide. New Delhi: BEE.

[7] BUREAU OF INDIAN STANDARDS (2005) IS SP 7: of India 2005. New Delhi: Bureau of Indian Standards.

[8] BURRIS, K.O. (2001) Senior fire prevention campaign. Fire Engineering, 154 (6), pp. 117-118.

[9] CENTER FOR HOUSING POLICY (2012) Housing an ageing population, are we prepared?. Washington DC: Centre for Housing Policy. Available from: http://www.nhc.org/media/files/AgeingReport2012.pdf [Accessed 15 April 2016].

[10] CHATTERJEE, M. (2009) Perception of housing environment among high rise dwellers of Kolkata city. Journal of the Indian Academy of Applied Psychology, 35(3), pp. 85-92.

[11] CHAUDHURI, A. and DAS, S. (2014) An Agile City for fragile people. In: Proceedings of International Symposium on Megacities, 11-14 November 2014.

[12] CHEEK, P., NIKPOUR, L. and NOWLIN, H. D. (2005) Ageing well with smart technology, Nursing Administration Quarterly. 29(4), pp. 329-338.

[13] CHOE, S.H. and LEE T.K. (2011) A study on building sustainable communities in high-rise and high-density apartments - Focused on living program. Building and Environment, 46(7), pp. 1428-1435.

[14] COURTNEY, K.L. (2008) Privacy and senior willingness to adopt smart home information technology in residential care facilities. Methods of Information in Medicine. 47(1), pp. 76-81.

[15]DAS, S., CHEW, M.Y.L. and POH, K.L. (2010) Multi-criteria decision analysis in building maintainability using analytical hierarchy process. Construction Management \& Economics, 28(10), pp. 1466-1433.

[16] DEMIRIS, G., RANTZ, M.J. AUD, M.A., MAREK, K.D., TYRER, H.W., SKUBIC, M. and HUSSAM, A.A. (2004) Older adults' attitudes towards and perceptions of 'smart home' technologies: A pilot study. Medical Informatics and the Internet in Medicine, 29(2), pp. 87-94.

[17]DTZ INDIA (2016). DTZ Research..[Online]. Available from: http:// www.dtz.com/India[Accessed: 17 April 2016].

[18]ELDER, A.T., SQUIRES, T.and BUSUTTIL, A. (1996) Fire fatalities in elderly people. Age \& Ageing, 25(3), pp. 214-216. 
[19] EMPORIS (2016) EMPORIS - building data and construction projects worldwide. [Online]. Available from: http://www .emporis.com [Accessed: 17 April 2016].

[20]FAUSSET, C.B., KELLY, A.J., ROGERS, W.A. and FISK, A.D. (2011) Challenges to Ageing in place: Understanding home maintenance difficulties. Journal of Housing for the Elderly, 25(2), pp. 125-141.

[21] FONAD, E., WAHLIN, T.B.R., HEIKKILA, K. and EMAMI, A. (2006) Moving to and living in a retirement home. Journal of Housing for the Elderly, 20(3), pp. 45-60.

[22] GHOSH,D. (2015) Special police unit to protect the elderly. Times of India. 3rd Jan, 2015. Available from: http://timesofindia.indiatimes.com/city/ kolkata/Special-police-unit-to-protect-the-elderly/articleshow/45736684. cms [Accessed: ??]

[23] GIFFORD, R. (2007) The consequences of living in high-rise buildings. Architectural Science Review, 50(1), pp. 2-17.

[24] GRANT THORNTON INDIA LLP and CONFEDRATION OF INDIAN INDUSTRY (2012) Report on Emerging trends in real estate: India 2012. New Delhi: Grant Thornton. Available from: http://gtw3 .grantthornton. in/assets/Emerging_Trends_in_Real_Estate_Sector-GrantThornton_CII_ Report_2012.pdf [Accessed 20 May 2016].

[25] GUPTA, R. and CHANDIWALA, S. (2011) A critical and comparative evaluation of $\mathrm{CO}_{2}$ emissions from national building stocks of developed and rapidly-developing countries - case studies of UK, USA, and India.In: HOORNWEG, D. et. al. (eds.). Cities and Climate Change: Responding to an Urgent Agenda. Vol. 2. Washington DC: The World Bank, pp. 74135.

[26] HANSMANN, U. et. al. (2003) Pervasive Computing, Heidelberg: Springer-Verlag Berlin .

[27]HUNT, M. E. and GUNTER-HUNT, G. (1986) Naturally occurring retirement communities. Journal of Housing for the Elderly, 3 (3/4), pp. $3-21$.

[28] HWANG, E., CUMMINGS, L., SIXSMITH, A. and SIXSMITH, J. (2011) Impacts of home modifications on Ageing-in-place. Journal of Housing for the Elderly, 25(3), pp. 246-257.

[29] INDIA. MINISTRY OF HOME AFFAIRS (2011) Provisional Population Totals Paper 1 of 2011 India - Series 1. New Delhi: Office of the Registrar General \& Census Commissioner.

[30] INDIA. New Delhi:MHUPA.Available from: http://mhupa.gov.in/ writereaddata/NUHHP_2007.pdf[uary]
Assessing the Need of Adaptive Changes for Emerging NORCs in Urban India 
Das, $\mathrm{S}$

Gupta, M

Bose, $\mathrm{S}$

[31] INDIA.()Available from [ember]

[32] INDIA. New Delhi: Available from: http://www.indiaenvironmentportal. org.in/files/file/elderly_in_india_3.pdf[]

[33] INDIA. MINISTRY OF STATISTICS AND PROGRAMME IMPLEMENTATION.New Delhi: Available from: http://www.mospi. gov.in/publication/disability-india-statistical-profile-2011-1[]

[34] INDIA. MINISTRY OF STATISTICS AND PROGRAMME IMPLEMENTATION..National Sample Survey Organisation.

[35] INDIA. MINISTRY OF STATISTICS AND PROGRAMME IMPLEMENTATION.HICCA:New Delhi: National Sample Survey Organisation.Available from: http://mospi.nic.in/sites/default/files/ publication_reports/507_final.pdf[]

[36] INDIA. MINISTRY OF STATISTICS AND PROGRAMME IMPLEMENTATION.National Sample Survey Organisation.

[37] INDIA. MINISTRY OF URBAN DEVELOPMENTUIS.New Delhi: Available from: http://icrier.org/pdf/FinalReport-hpec.pdf[]

[38] JAI PRAKASH, I. (1999) Ageing in India. Geneva: WHO.

[39] KIM, S.K., LEE, Y.M. and YIM, M.S. (2009) High-tech amenities for the elderly: The technological assistance needs of elderly Koreans Ageing at home. Journal of Housing for the Elderly, 23(3), pp. 204-226.

[40] KRISHNASWAMY, B., SEIN, U.T., MUNODAWAFA, D., VARGHESE, C., VENKATARAMAN, K. and ANAND, L. (2008) Ageing in India. Ageing International, 32(4), pp. 258-268.

[41] LABERG, T., ASPELUND, H. and THYGESEN, H. (2005) Smart home technology: Planning and management in municipal services. Oslo: Directorate for Social and Health Affairs, the Delta Centre.LAWTON, M. P. (1990) Knowledge resources and gaps in housing for the aged. In: TILSON, D. (ed.), Aging in place: supporting the frail elderly in residential environments. Glenview, IL: Scott, Foresman.

[42] MAREK, K. D., POPEJOY, L., PETROSKI, G., MEHR, D., RANTZ, M., and LIN, W. (2005) Clinical outcomes of Ageing in place. Nursing Research, 54(3), pp. 202-211.

[43] MCNEIL, M. A., IYER, M., MEYERS, S., LETSCHERT, V. E. and MCMAHON, J. E. (2008) Potential benefits from improved energy efficiency of key electrical products: The case of India, Energy Policy, 36(9), pp. 3467-3476. 
[44] MELLOR, D., FIRTH, L. and MOORE, K. (2008) Can the internet improve the well-being of the elderly? Ageing International, 32(1), 2542.

[45] MUHURI, S. and BASU, S. (2014) Social interaction and neighbours' relation in high-rise housings in Kolkata, India - Findings from focus group survey. In: Proceedings of International Symposium on Megacities, Kolkata, 11-14 November 2014.

[46] NEWMAN, O. (1972) Defensible space: Crime prevention through urban design. New York: Macmillan.

[47] NIE, N. H., and ERBRING, L. (2002) Internet and society: A preliminary report. Stanford, CA: Stanford Institute for the Quantitative Study of Society.

[48] NORMOYLE, J.B. and FOLEY, J.M. (1988) The defensible space model of fear and elderly public housing residents. Environment \& Behaviour, 20(1), pp. 50-74.

[49] PALTASINGH, T. and TYAGI, R. (2012) Demographic Transition and Population Ageing: Building an Inclusive Culture. Social Change, 42(3), pp. 391-409.

[50]RAAD, M.W. and YANG, L.T. (2009) A ubiquitous smart home for elderly. Information Systems Frontiers, 11(5), pp. 529-536.

[51] RENAUT, S. and OGG, J. (2011) Adapting the home or adapting to the home? WS-15 : Housing and Living Condition of Ageing Populations, In: Proceedings of the 23rd European Network for Housing Research (ENHR) Conference 2011, Toulouse, 5-8 July 2011. Delft: ENHR.

[52] SEIDEL, D., CRILLY, N., MATTHEWS, F. E., JAGGER, C., BRAYNE, C., and CLARKSON, P. J. (2009) Patterns of functional loss among older people: A prospective analysis. Human Factors, 51(5), pp. 669-680.

[53] SINGAPORE. BUILDING AND CONSTRUCTION AUTHORITY (2007) Code on Accessibility in the Built Environment 2007. Singapore: BCA. Available from: http://www.bca.gov.sg/BarrierFree/others/ AccessibilityCode2007.pdf [Accessed: 9 January 2016].

[54] SIVAMURTHY, M. and WADAKANNAVAR, A.R. (2001) Care and support for the elderly population in India: results from a survey of the aged in rural north Karnataka (India). In: Proceedings of the 24th IUSSP General Population Conference, Salvador, 18-24 August, 2001. Paris: International Union for the Scientific Study of Population. UNITED NATIONS (2002) Political declaration and Madrid international plan of action on ageing, New
Assessing the Need of Adaptive

Changes for Emerging NORCs in Urban India

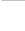


Das, $\mathrm{S}$

Gupta, M

Bose, $\mathrm{S}$
York: UN.UNITED NATIONS (2009) World Population Ageing 2009: ESA/P/WP/212, New York: UN.

[55] VICTORIAN GOVERNMENT. DEPARTMENT OF HUMAN SERVICES (2000) Aged Care Residential Services: Generic Brief. Melbourne: Aged, Community \& Mental Health Division.

[56] WAGNILD, G. (2012) Chapter 4: Growing old at home. In: PASTALAN, L.A. and SCHWARZ, B. (eds.) Housing choices and well-being of older adults: Proper fit. 2nd ed. New York: Routledge, pp. 71-84

[57] WORLD HEALTH ORGANISATION (2007) Global age-friendly cities: a guide. Geneva: WHO.

[58] WINTER, D.E. (2004) Development of an elderly high-rise fire safety plan for the city of Rochester fire department: Leading community risk reduction. New York: National Fire Academy. Available from: https:// nfa.usfa.fema.gov/pdf/efop/efo37497.pdf [Accessed 15 April 2015].

[59] YUEN, B., YEH, A., APPLOLD, S.J., EARL, G., TING, J. and KWEE, L.K. (2006). High-rise living in Singapore public housing. Urban Studies, 43(3), pp. 583-600. 